07

\title{
Транспортные свойства пленок графена, выращенных методом термодеструкции поверхности SiC (0001) в среде аргона
}

\author{
(C) С.П. Лебедев ${ }^{1}$, И.А. Елисеев ${ }^{2}$, В.Ю. Давыдов ${ }^{1}$, А.Н. Смирнов ${ }^{1,3}$, \\ В.С. Левицкий ${ }^{4}$, М.Г. Мынбаева ${ }^{1}$, М.М. Кулагина ${ }^{1}$, \\ B. Hähnlein ${ }^{5}$, J. Pezoldt ${ }^{5}$, A.A. Лебедев ${ }^{1}$ \\ ${ }^{1}$ Физико-технический институт им. А.Ф. Иоффре РАН, \\ Санкт-Петербург, Россия \\ ${ }^{2}$ Санкт-Петербургский государственный университет, \\ Санкт-Петербург, Россия \\ ${ }^{3}$ Санкт-Петербургский национальный исследовательский университет \\ информационных технологий, механики и оптики, \\ Санкт-Петербург, Россия \\ ${ }^{4}$ ООО «НТЦ тонкопленочных технологий в энергетике», \\ Санкт-Петербург, Россия \\ ${ }^{5}$ FG Nanotechnologie, Institut für Mikro- und Nanotechnologien und Institut \\ für Mikro- und Nanoelektronik, Technische Universität IImenau, \\ Ilmenau, Germany \\ E-mail: lebedev.sergey@mail.ioffe.ru
}

Поступило в Редакцию 1 июня 2017 г.

Представлены результаты исследования транспортных свойств пленок графена, полученных методом термодеструкции поверхности $4 H-\mathrm{SiC}$ (0001) в атмосфере аргона. Величина концентрации носителей заряда в исследуемом графене составила $7 \cdot 10^{11}-1 \cdot 10^{12} \mathrm{~cm}^{-2}$, а максимальные значения подвижности электронов приблизились к $6000 \mathrm{~cm}^{2} /(\mathrm{V} \cdot \mathrm{s})$. Достигнутые величины подвижности близки к теоретически рассчитанным значениям для графена на $\mathrm{Si}$-грани с собственной проводимостью при $T=300 \mathrm{~K}$ без водородной интеркаляции.

DOI: 10.21883/PJTF.2017.18.45035.16895

В настоящее время графен позиционируется как один из самых перспективных материалов для применения в качестве основы компонентной базы активно развивающейся наноэлектроники [1]. Использование графена позволит преодолеть ограничения, свойственные 
традиционной кремниевой электронике, которые связаны со степенью миниатюризации и энергопотребления устройств. Основанием для этого служат уникальные физические характеристики данного материала, среди которых одной из важнейших является чрезвычайно высокая подвижность носителей заряда при комнатной температуре.

Наиболее перспективной технологией синтеза графена, которая позволяет получать высококачественный материал и в то же время может быть интегрирована в промышленное производство, представляется термодеструкция поверхности полуизолирующих подложек карбида кремния ( $\mathrm{SiC})$. Процесс термодеструкции может осуществляться как в вакууме [2-4], так и в среде инертного газа [5-8]. На ранних этапах исследований структур графен/SiC нами использовалась технология получения графена в высоком вакууме [2,3]. В настоящей работе представлены результаты исследований транспортных свойств графеновых пленок, полученных с использованием усовершенствованной технологии роста в среде инертного газа (аргона), и проведено их сравнение с данными для пленкок графена, выращенных в вакууме. Мы также приводим результаты сравнения структурных характеристик, полученных из данных комбинационного рассеяния света (КРС), для пленок, выращенных в аргоне и вакууме.

Различие технологий получения графена на $\mathrm{SiC}$ в вакууме и в аргоне не ограничивается только использованием разной среды роста. Различаются также температура роста и ориентация поверхности подложки, на которой идет формирование графена. В работах [2,3] при росте в вакууме применялись следующие технологические параметры: остаточное давление в камере $10^{-6}$ Torr, температура роста $1400-1500^{\circ} \mathrm{C}$, время роста $15 \mathrm{~min}$. При этом для роста графена использовалась $C$-грань (ориентация поверхности - 0001) подложки $\mathrm{SiC}$. При росте в среде аргона температура роста была увеличена до $1800-1850^{\circ} \mathrm{C}$, время роста составило $10 \mathrm{~min}$, давление аргона в ростовой камере 760 Torr, a сам рост осуществлялся на $\mathrm{Si}$-грани (ориентация поверхности (0001)) подложки. Изменение технологических параметров обусловлено изменением кинетики роста вследствие частичного подавления аргоном сублимации компонентов карбида кремния с поверхности подложки. Благодаря этому появилась возможность использовать более термически стабильную $\mathrm{Si}$-грань подложки $\mathrm{SiC}$, что в свою очередь привело к снижению скорости роста графена и позволило получать однородные монослойные (ML) графеновые пленки [9].

5 Письма в ЖТФ, 2017, том 43, вып. 18 


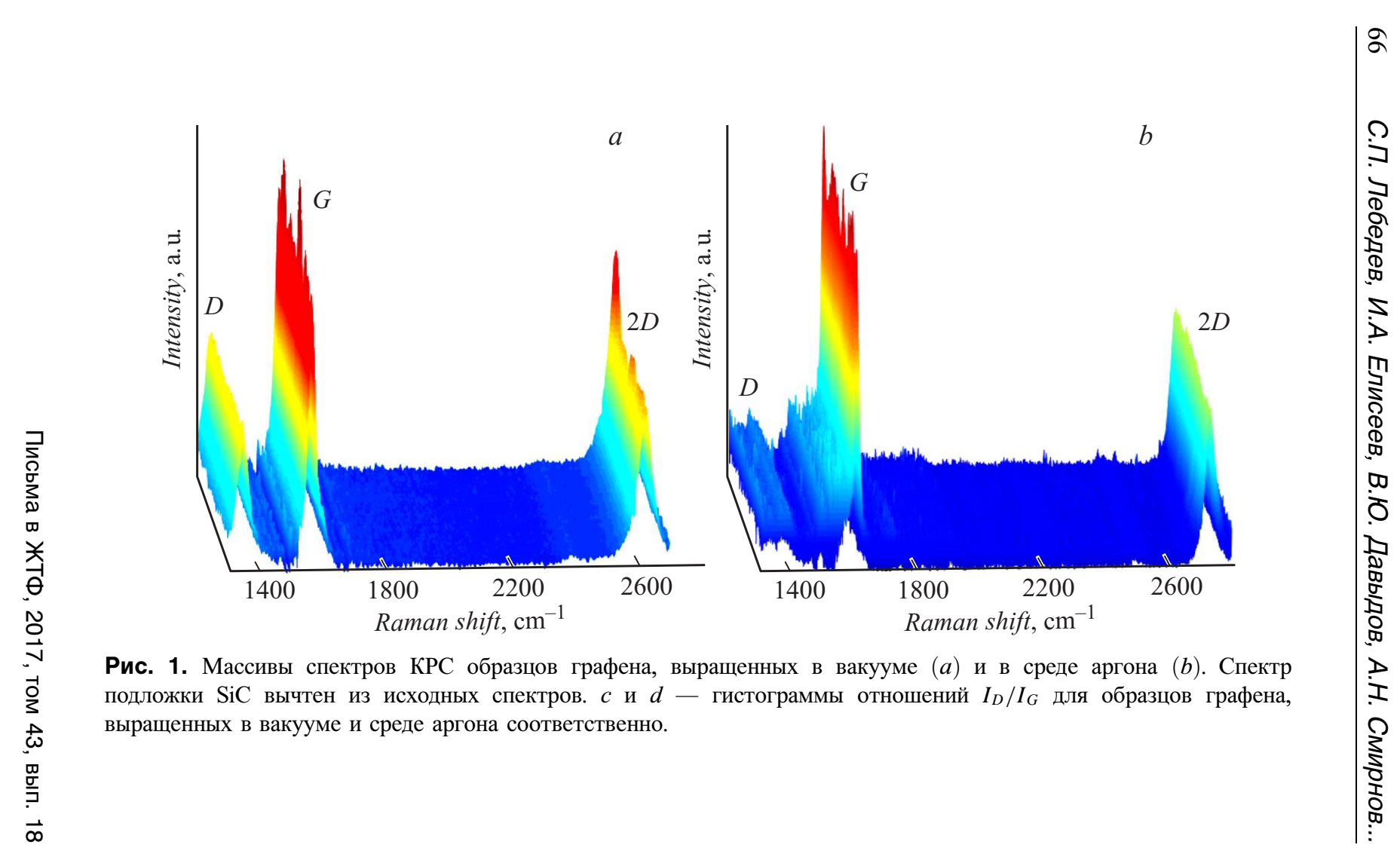




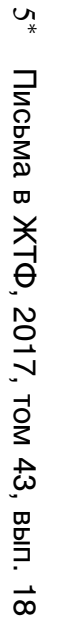
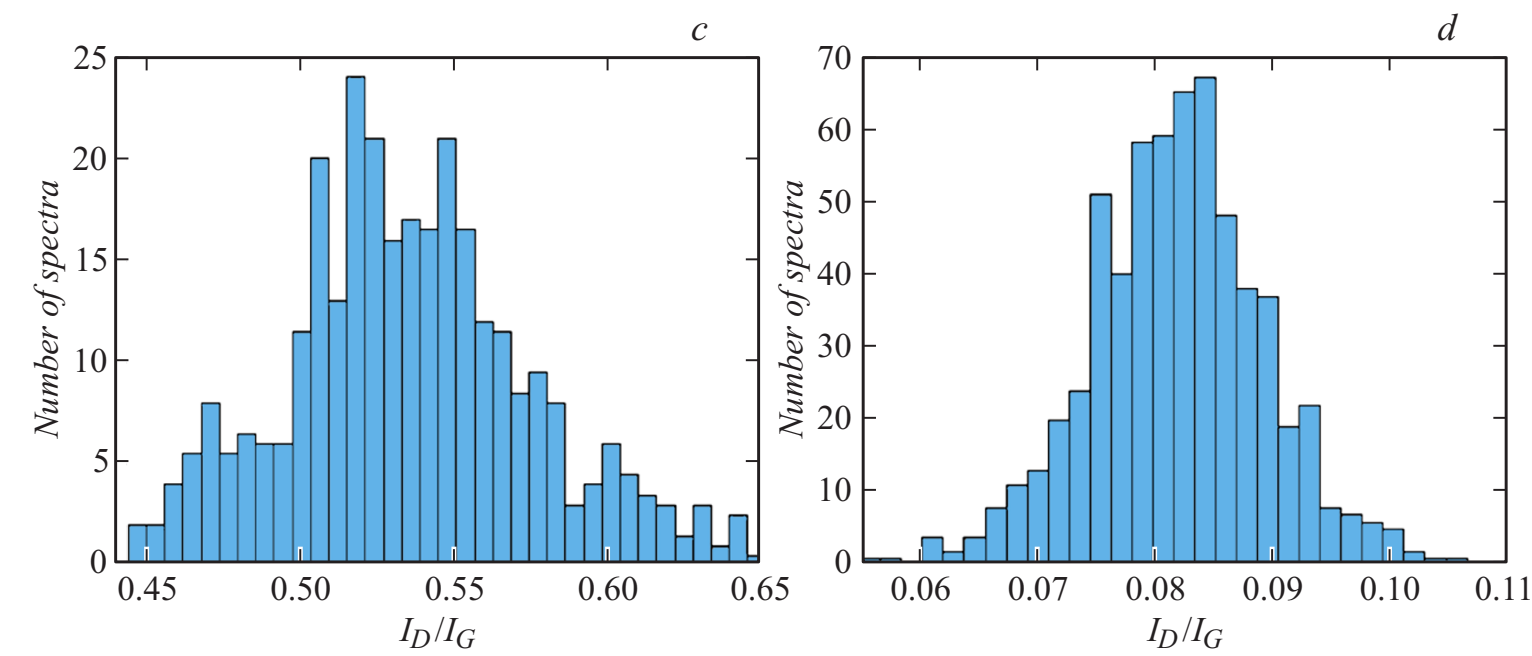

Рис. 1 (продолжение). 
Сравнение структурных и транспортных характеристик графеновых пленок, выращенных в вакууме и в среде аргона

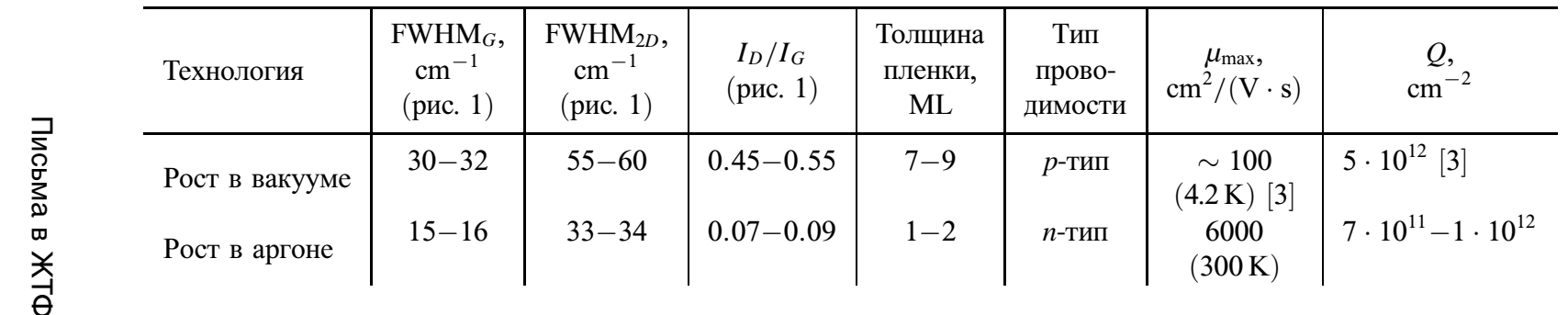


На рис. 1 представлены массивы спектров КРС пленок графена, выращенных методом термодеструкции политипа $4 H-\mathrm{SiC}$ в вакууме и в среде аргона. Спектры были измерены на площади образцов размером $12.5 \times 12.5 \mu \mathrm{m}$. В таблице приведены средние величины ширин на половине высоты (FWHM) фононных линий $G$ и $2 D$, позволяющие оценить структурное совершенство двух пленок. Существенно бо́льшие значения $\mathrm{FWHM}_{G}$ для пленки, выращенной в вакууме, указывают на ее более низкое структурное совершенство. Об этом же свидетельствует величина отношения интегральных интенсивностей $I_{D} / I_{G}$, используемая для количественной оценки степени дефектности графена [10]. Видно, что максимум распределения отношения $I_{D} / I_{G}$ для пленки, выращенной в вакууме, находится вблизи 0.5 (рис. 1,c), что соответствует значению концентрации дефектов в кристаллической решетке $N_{d} \sim 5 \cdot 10^{11} \mathrm{~cm}^{-2}$ [11]. В то же время для пленки, выращенной в среде аргона, этот параметр существенно ниже $\sim 0.08$ (рис. $1, d$ ), а значит, ниже и концентрация дефектов в кристаллической решетке $\left(N_{d}<10^{10} \mathrm{~cm}^{-2}\right)$. Было также установлено, что линия $2 D$ в большинстве спектров для пленки, выращенной в среде аргона, имеет симметричный вид и хорошо аппроксимируется одиночным контуром Лоренца, что является признаком однослойного графена [12]. Толщина графеновой пленки, полученной методом термодеструкции в вакууме на $C$-грани, оценивается в 7-9 монослоев [2].

Для подготовки пленок графена к проведению электрофизических измерений на поверхности образцов формировались тестовые структуры в геометрии холловского моста (Hall-bar). Топология требуемых структур была создана с применением стандартной процедуры процесса контактной фотолитографии с использованием специально разработанного комплекта фотошаблонов.

Измерения концентрации и подвижности носителей заряда в графене, выращенном в среде аргона, осуществлялись при комнатной температуре с использованием установки Accent HL5500PC. Сила магнитного поля составляла $0.314 \mathrm{~T}$. По знаку холловского сигнала для исследованных структур был установлен электронный тип проводимости. Величина концентрации носителей заряда в двумерном электронном газе $(Q)$ графена составила $7 \cdot 10^{11}-1 \cdot 10^{12} \mathrm{~cm}^{-2}$, а максимальные значения подвижности электронов $\left(\mu_{\max }\right)$ в исследуемых пленках достигали уровня $6000 \mathrm{~cm}^{2} /(\mathrm{V} \cdot \mathrm{s})$. В таблице для сравнения приведены значения подвижности и концентрации носителей заряда

Письма в ЖТФ, 2017, том 43, вып. 18 


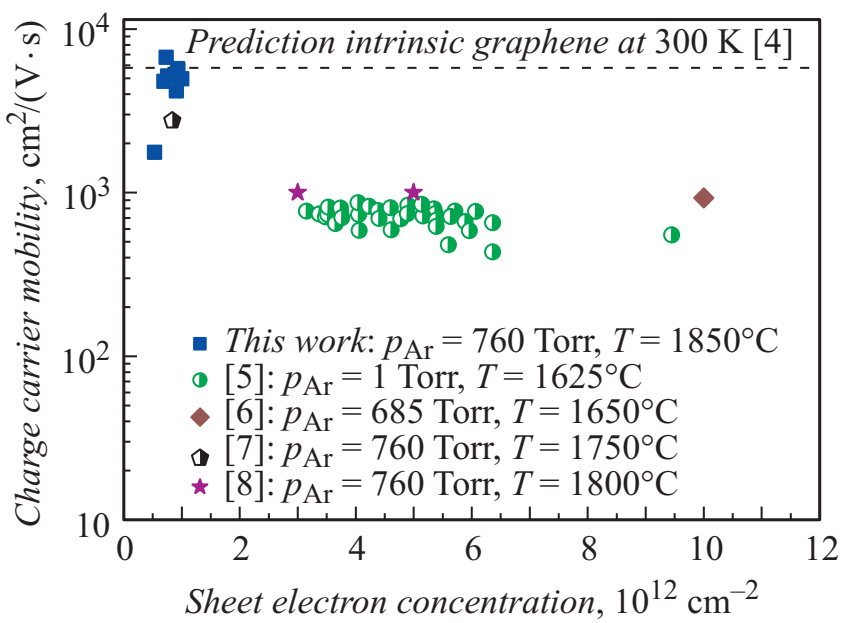

Pис. 2. Значения подвижности носителей заряда, полученные разными исследовательскими группами на неинтеркалированном графене, выращенном при различных технологических условиях.

для пленок, выращенных в вакууме [3], которые, согласно данным холловских измерений, имеют дырочный тип проводимости. Несмотря на то что измерения подвижности носителей заряда для графена, полученного в вакууме, проводились при температуре жидкого гелия, ее величина более чем на порядок уступает значениям подвижности, измеренным при комнатной температуре в пленках, выращенных в среде аргона.

На рис. 2 представлена зависимость величины подвижности электронов от концентрации носителей заряда в двумерном электронном газе в неинтеркалированном графене, выращенном в среде аргона на Si-грани. График построен с использованием данных измерений, полученных разными исследовательскими группами на графене, выращенном при различных технологических условиях [5-8]. Четко прослеживается, что подвижность электронов в графене увеличивается с уменьшением концентрации носителей заряда в двумерном электронном газе. Значения подвижности в выращенных пленках с концентрацией электронов меньше $1 \cdot 10^{12} \mathrm{~cm}^{-2}$, полученные авторами 
настоящей работы, достигают теоретически рассчитанных величин для графена с собственной проводимостью при $T=300 \mathrm{~K}$ без водородной интеркаляции [4].

Таким образом, можно сделать вывод, что метод термодеструкции поверхности $\mathrm{SiC}(0001)$ в среде аргона при определенных технологических условиях роста (давление аргона 700-760 Torr, температура роста $1800-1850^{\circ} \mathrm{C}$, время роста $10 \mathrm{~min}$ ) позволяет получать высококачественные однослойные пленки графена, обладающие значениями подвижности носителей заряда, близкими к теоретически предсказанным величинам для Si-грани. Это открывает возможность использования созданной технологии для производства приборов на основе графена.

С.П. Лебедев выражает благодарность за поддержку стипендией Президента РФ для молодых ученых и аспирантов (приказ № 1684 от 30 декабря 2016 г.).

\section{Список литературы}

[1] Novoselov K.S., Fal'ko V.I., Colombo L., Gellert P.R., Schwab M.G., Kim K. // Nature. 2012. V. 490. P. 192-200.

[2] Агринская Н.В., Березовеи, В.А., Козуб В.И., Котоусова И.С., Лебедев А.А., Лебедев С.П., Ситникова А.А. // ФТП. 2013. Т. 47. С. 273-278.

[3] Лебедев А.А., Агринская Н.В., Лебедев С.П., Мынбаева М.Г., Петров В.Н., Смирнов А.Н., Стрельчук А.М., Титков А.Н., Шамшур Д.В. // ФТП. 2011. T. 45 C. $634-638$.

[4] Tedesco J.L., VanMill B.L., Myers-Ward R.L., McCrate J.M., Kitt S.A., Campbell P.M., Jernigan G.G., Culbertson J.C., Eddy C.R., Gaskill D.K. // Appl. Phys. Lett. 2009. V. 95. P. 122102.

[5] Robinson J.A., Hollander M., LaBella M., III, Trumbull K.A., Cavalero R., Snyder D.W. // Nano Lett. 2011. V. 11. P. 3875-3880.

[6] Emtsev K.V., Bostwick A., Horn K., Jobst J., Kellogg G.L., Ley L., McChesney J.L., Ohta T. Reshanov S.A. Röhrl J., Rotenberg E., Schmid A.K., Waldmann D., Weber H., Seyller T. // Nature Mater. 2009. V. 8. P. 203-207.

[7] Kruskopf M., Pakdehi D.M., Pierz K., Wundrack S., Stosch R., Dziomba T., Götz M., Baringhaus J., Aprojanz J., Tegenkamp C., Lidzba J., Seyller T., Hohls F., Ahlers F.J., Schumacher H.W. // 2D Mater. 2016. V. 3. P. 041002.

[8] Händel B., Hähnlein B., Göckeritz R., Schwierz F., Pezoldt J. // Appl. Surf. Sci. 2014. V. 291. P. 87-92.

Письма в ЖТФ, 2017, том 43, вып. 18 
[9] Давыдов В.Ю., Усачёв Д.Ю., Лебедев С.П., Смирнов А.Н., Левицкий В.С., Елисеев И.А., Алексеев П.А., Дунаевский М.С., Вилков О.Ю., Рыбкин А.Г., Лебедев А.А. // ФТП. 2017. Т. 51. С. 1116-1124.

[10] Cançado L.G., Jorio A., Martins Ferreira E.H., Stavale F., Achete C.A., Capaz R.B., Moutinho M.V.O., Lombardo A., Kulmala T.S., Ferrari A.C. // Nano Lett. 2011. V. 11. P. 3190-3196.

[11] Ganesan K., Subrata Ghosh, Nanda Gopala Krishna, Ilango S., Kamruddin M., Tyagi A.K. // Phys. Chem. Chem. Phys. 2016. V. 18. P. 22160-22167.

[12] Ferrari A.C., Basko D.M. // Nature Nanotechnol. 2013. V. 8. P. 235-246. 